\title{
Fetal alcohol spectrum disorder: Canadian guidelines for diagnosis
}

\author{
Albert E. Chudley, Julianne Conry, Jocelynn L. Cook, Christine Loock, \\ Ted Rosales, Nicole LeBlanc
}

\begin{abstract}
THE DIAGNOSIS OF FETAL ALCOHOL SPECTRUM DISORDER (FASD) is complex and guidelines are warranted. A subcommittee of the Public Health Agency of Canada's National Advisory Committee on Fetal Alcohol Spectrum Disorder reviewed, analysed and integrated current approaches to diagnosis to reach agreement on a standard in Canada. The purpose of this paper is to review and clarify the use of current diagnostic systems and make recommendations on their application for diagnosis of FASD-related disabilities in people of all ages. The guidelines are based on widespread consultation of expert practitioners and partners in the field. The guidelines have been organized into 7 categories: screening and referral; the physical examination and differential diagnosis; the neurobehavioural assessment; and treatment and follow-up; maternal alcohol history in pregnancy; diagnostic criteria for fetal alcohol syndrome (FAS), partial FAS and alcohol-related neurodevelopmental disorder; and harmonization of Institute of Medicine and 4-Digit Diagnostic Code approaches. The diagnosis requires a comprehensive history and physical and neurobehavioural assessments; a multidisciplinary approach is necessary. These are the first Canadian guidelines for the diagnosis of FAS and its related disabilities, developed by broad-based consultation among experts in diagnosis.
\end{abstract}

$\mathrm{I}$ $\mathrm{n}$ this document, we discuss the diagnostic approach to disabilities associated with prenatal alcohol exposure. Fetal alcohol spectrum disorder (FASD), along with its most visible presentation, fetal alcohol syndrome (FAS), is a serious health and social concern to Canadians. FASD is an umbrella term describing the range of effects that can occur in an individual whose mother drank alcohol during pregnancy. These effects may include physical, mental, behavioural and learning disabilities with lifelong implications. The term FASD is not intended for use as a clinical diagnosis.

FASD is the result of maternal alcohol consumption during pregnancy and has implications for the affected person, the mother, the family and the community. Since FAS was first described in $1973,{ }^{1}$ it has become apparent that it is complex; affected people exhibit a wide range of expression, from severe growth restriction, intellectual disability, birth defects and characteristic dysmorphic facial features to normal growth, facial features and intellectual abilities, but with lifelong deficits in several domains of brain function. FASD requires a medical diagnosis in the context of a multidisciplinary assessment. FASD itself is not a diagnostic term. The purpose of this paper is to review and clarify the use of the current diagnostic systems and make recommendations on their application for diagnosis of FASD-related disabilities in people of all ages. For a description of the characteristics and the natural course of FASD, consult some of the broader reviews. ${ }^{2-7}$

\section{Epidemiology of FASD}

The prevalence of FAS in the United States has been reported as $1-3$ per 1000 live births and the rate of FASD as 9.1 per 1000 live births..$^{8-11}$ However, diagnosis may often be delayed or missed entirely. ${ }^{2}$

There are no national statistics on the rates of FASD in Canada, although studies have estimated its prevalence in small populations. In an isolated Aboriginal community in British Columbia, FASD prevalence was 190 per 1000 live births. ${ }^{12}$ In northeastern Manitoba, an incidence of about 7.2 per 1000 live births was found. ${ }^{13}$ In another Manitoba study in a First Nations community,$^{14}$ the prevalence of FAS and partial FAS was estimated to be 55-101 per 1000 . In their survey, Asante and Nelms-Matzke ${ }^{15}$ estimated the rate of FAS and related effects at 46 per 1000 native Canadian children in the Yukon and 25 per 1000 in northern British Columbia. Based on referrals to a diagnostic clinic in Saskatchewan, the rate of FAS was estimated at 0.589 per 1000 live births in $1988-1992$ and 0.515 per 1000 in 1973-1977. ${ }^{16}$ However, none of these data should be generalized to other communities, other populations or the Canadian population in general.

\section{Risk factors}

A common misconception is that FASD is associated with ethnocultural background. However, the data suggest that risk factors for prenatal alcohol exposure include higher maternal age and lower education level, prenatal exposure to cocaine and smoking, custody changes, lower socioeconomic status and paternal drinking and 
drug use at the time of pregnancy; ${ }^{17}$ and reduced access to prenatal and postnatal care and services, inadequate nutrition and a poor developmental environment (e.g., stress, abuse, neglect). ${ }^{18}$

In a 5-year follow-up study of birth mothers of children with full FAS, Astley and colleagues ${ }^{19}$ found that these women came from diverse racial, educational and economic backgrounds. They were often challenged by untreated or under-treated mental health concerns, they were socially isolated, they were victims of abuse and they had histories of severe childhood sexual abuse.

Because there are no large-scale studies of risk factors and because risks are interrelated and could be different for different populations, it is difficult to provide accurate figures for relative risk. However, the most important risk factor for FASD is related to high blood-alcohol concentration: the timing of exposure during fetal development, the pattern of consumption, i.e., binge drinking (4 or more drinks per occasion) and the frequency of use. Although there seems to be no definite threshold of exposure, there appears to be a dose-response relation. ${ }^{17,20,21}$

\section{Importance of early diagnosis}

An early diagnosis is essential to allow access to interventions and resources that may mitigate the development of subsequent "secondary disabilities" (e.g., unemployment, mental health problems, trouble with the law, inappropriate sexual behaviour, disrupted school experience) among affected people. ${ }^{22}$ Furthermore, an early diagnosis will also allow appropriate intervention, counselling and treatment for the mother and may prevent the birth of affected children in the future..$^{23}$ It may also prompt caregivers to seek diagnosis and support for previously undiagnosed siblings. A review of medical and behavioural management of those with FASD can be found in other sources. ${ }^{3,24}$ Astley and Clarren ${ }^{25}$ suggest that accurate and timely diagnosis is essential to improve outcome, as misclassification leads to inappropriate patient care, increased risk of secondary disabilities, missed opportunities for prevention and inaccurate estimates of incidence and prevalence. Together, these inaccuracies could hinder efforts to allocate sufficient social and health care services to the vulnerable populations and preclude accurate assessment of primary prevention efforts.

Because of limited capacity and expertise and the need to involve several professionals in a comprehensive multidisciplinary diagnostic evaluation, only a fraction of those affected currently receive a diagnosis. Results ${ }^{26}$ from the Canadian national survey regarding knowledge and attitudes of health professionals suggest that standardized guidelines for diagnosis and further professional education and training are needed for practitioners to participate in diagnosis. In response to these concerns, Health Canada's National Advisory Committee on FASD, along with experts and practitioners in FAS diagnosis and treatment, present the following guidelines for diagnosis.

\section{Process of guideline development}

These guidelines are the result of more than 10 faceto-face consultations with Canadian and American experts in the diagnosis of FAS and its related disabilities (Appendix 1). Many of the participants are currently providing diagnostic services across Canada. Review and feedback were provided by a diverse group of individuals; professional organizations and societies; and provincial, territorial and federal levels of government. Guidelines are presented in 6 areas related to the diagnostic process: 1 . screening and referral; 2 . the physical examination and differential diagnosis; 3 . neurobehavioural assessment; 4. treatment and follow-up; 5. maternal alcohol history in pregnancy; and 6. diagnostic criteria for FAS, partial FAS and alcohol-related neurodevelopmental disorder. We also include recommendations for harmonization of the 2 main approaches to diagnosis.

There are multiple approaches to diagnosis, and the working group sought to integrate these to achieve consistent diagnoses across Canada. Current knowledge of the complexity of the disabilities associated with prenatal alcohol exposure dictates that a comprehensive, multidisciplinary assessment is necessary to make an accurate diagnosis and provide recommendations for management. We are recommending such a multidisciplinary approach. This approach will also allow for collection of Canadian data for estimating incidence and prevalence of FASD. This information is essential to identify the need for and the development of appropriate prevention and intervention programs and services.

\section{Background and terminology for the diagnosis of FAS}

The first recognition of a variety of birth defects and developmental disabilities in offspring born to alcoholic parents is attributed to Lemoine and colleagues. ${ }^{27}$ A specific pattern of birth defects following maternal alcohol exposure was described in the United States. ${ }^{1,28}$ The specific pattern, referred to as FAS, consists of facial abnormalities (smooth philtrum [the space between the upper lip and the nose], thin vermilion border [the exposed mucosal, or red part, of the upper lip], short palpebral fissures), impaired prenatal or postnatal growth (or both) and central nervous system or neurobehavioural disorders. Alcohol probably acts through multiple mechanisms and a range of disabilities has been observed in the absence of dysmorphic features reflecting varying degrees of damage during fetal development; undoubtedly, timing and degree of exposure are important variables that contribute to the variation. Thus, the term "suspected fetal alcohol effects" (FAE) was created. ${ }^{29}$ These "effects" were further delineated by the United States' Institute of Medicine (IOM), which published recommendations in 1996 for diagnosis of FAS in consultation with a panel of experts. ${ }^{4}$ 
The diagnostic categories presented were: FAS with and without a confirmed history of alcohol exposure, partial FAS, alcohol-related birth defects (ARBD), and alcohol-related neurodevelopmental disorder (ARND) (Table 1).

In the late 1990s, another diagnostic strategy was developed by Astley and Clarren. ${ }^{25,30}$ They created a 4-Digit Diagnostic Code using data from the Washington State Fetal Alcohol Syndrome Diagnostic and Prevention Network of clinics. The system uses quantitative, objective measurement scales and specific case definitions. The 4 digits in the code reflect the magnitude of expression or severity of the 4 key diagnostic features of FAS in the following order: growth deficiency; the FAS facial phenotype; central nervous system damage or dysfunction; gestational exposure to alcohol. The magnitude of expression of each feature is ranked independently on a 4-point Likert scale with 1 reflecting complete absence of the feature and 4 reflecting its extreme expression. The 4-Digit Diagnostic Code is now being used for diagnosis, screening and surveillance in clinics throughout the United States and Canada. Terminology from Astley's 2004 revision of the 4-Digit Diagnostic Code are used in this article.*

Although the approaches are different, the underlying, fundamental criteria of the IOM and the 4-Digit Diagnostic Code are similar. Some clinics are choosing to integrate the diagnostic tools and precision reflected in the 4-Digit Diagnostic Code with the diagnostic categories and language recommended by the IOM committee. Although both IOM criteria and the 4-Digit Diagnostic Code have been published, many clinicians still use the less desirable and potentially misleading gestalt approach (Table 2).

\section{The diagnostic process}

The diagnostic process consists of screening and referral, the physical examination and differential diagnosis, the neurobehavioural assessment and treatment and follow-up. Because of the complexity and the range of expression of dysfunction related to prenatal alcohol exposure, a multidisciplinary team is essential for an accurate and comprehensive diagnosis and treatment recommendations. The assessment process begins with recognition of the need for diagnosis and ends with implementation of appropriate recommendations. The multidisciplinary diagnostic team can be geographic, regional or virtual; it can also accept referrals from distant communities and carry out an evaluation using telemedicine.

The core team may vary according to the specific context, but ideally it should consist of the following professionals with appropriate qualifications, training and experience in their particular discipline:

\footnotetext{
*Astley SJ. Diagnostic Guide for Fetal Alcohol Spectrum Disorders: The 4-Digit Diagnostic Code (3rd edition). Seattle: University of Washington Publication Services; 2004.
}

- Coordinator for case management (e.g., nurse, social worker).

- Physician specifically trained in FASD diagnosis.

- Psychologist.

- Occupational therapist.

- Speech-language pathologist.

Additional members may include addiction counsellors, childcare workers, cultural interpreters, mental health workers, parents or caregivers, probation officers, psychiatrists, teachers, vocational counselors, nurses, geneticists or dysmorphologists, neuropsychologists, family therapists.

\section{Comments}

Clearly, funding for development, training and maintenance of multidisciplinary diagnostic teams is necessary so that major centres will have the expertise and capacity to serve their communities. To optimize the outcome of the diagnosis, the community and the family must be prepared, ready to participate in, and be in agreement with the diagnostic assessment. The diagnostic process should be sensitive to the family's and the caregiver's needs. In each community, referrals must be evaluated and their level of priority established. The family and guardian must be in agreement on the purpose of diagnosis. They must be made aware of the potential psychosocial consequences of a diagnosis of FASD (e.g., increasing a sense of guilt and anger, especially with the birth mother, or potential stigmatization of the child). The family or guardian will likely need help to move confidently through the diagnostic process. This help might include some preparatory education concerning FASD and linking them with community supports and resources.

Information from multiple sources (e.g., school records, hospital records, social services, previous assessments) should be obtained; this might involve meetings with relevant professionals who know the patient (e.g., teachers, physicians, social workers, psychologists). Other relevant documentation would include birth and pregnancy records, medical and hospital records, adoption records, academic records, achievement tests, developmental assessments, psychological and psychometric assessments, legal reports and documentation of the family history.

The comprehensive assessment by the diagnostic team provides important information about the individual's unique needs and allows interventions to be tailored to his or her strengths and challenges. The post-diagnostic report should state the basis for the diagnosis by including the history of alcohol use, the physical criteria and the psychological data that support it.

Multidisciplinary teams work with community partners and resources to develop and implement management plans to maximize the potential of the affected individual. Following assessment, a report containing recommendations should be made available to caregivers, educators, and biological families, as well as other appropriate indi- 
viduals who work with the child (i.e., daycare workers, early intervention workers, social workers, etc). The team findings should be discussed with the guardian. Older children who have the cognitive ability should have the opportunity to learn about their diagnosis from the team. The team might also take on the responsibility for facilitating and providing follow-up with the family and community resources regarding outcomes of the recommendations. Ultimately, the diagnostic process will result in concrete management recommendations to improve the lives of the affected individuals, their families and the communities.

Canada is a large country with vast distances between communities, some of which are remote and isolated. Specialists providing consultation to remote areas require specialized training in FASD assessment and need to link with centres that have multidisciplinary teams to assist in the diagnostic process. A number of tools may be useful for distant diagnosis. More frequent use of telemedicine, for example, will allow assessment of children in distant communities. ${ }^{31}$ Other examples include the use of digital photographs ${ }^{32,33}$ and 3-D laser surface scanning ${ }^{34,35}$ sent electronically to teams in larger centres.
We recognize that there is currently a limited capacity even in some large communities in Canada to provide a multidisciplinary team-based approach to FAS diagnosis. Professionals should make the best use of available resources and expertise to provide an accurate assessment and treatment plan for affected individuals and their families, recognizing the key role of psychology.

\section{Screening and referral}

\section{Recommendations}

1.1 All pregnant and post-partum women should be screened for alcohol use with validated screening tools (i.e., T-ACE, TWEAK) by relevant health care providers. Women at risk for heavy alcohol use should receive early brief intervention (i.e., counselling).

1.2 Abstinence should be recommended to all women during pregnancy, as the mother's continued drinking during pregnancy will put the fetus at risk for effects related to prenatal alcohol exposure.

1.3 Referral of individuals for a possible FASD-related diagnosis should be made in the following situations:

\section{Table 1: Institute of Medicine diagnostic criteria for fetal alcohol syndrome and alcohol-related effects ${ }^{4}$}

\section{Fetal alcohol syndrome (FAS)}

1. FAS with confirmed maternal alcohol exposure*

A. Confirmed maternal alcohol exposure*

B. Evidence of a characteristic pattern of facial anomalies that includes features such as short palpebral fissures and abnormalities in the premaxillary zone (e.g., flat upper lip, flattened philtrum and flat midface)

C. Evidence of growth retardation, as in at least one of the following:

- low birth weight for gestational age

- decelerating weight over time not due to nutrition

- disproportional low weight-to-height ratio

D. Evidence of central nervous system neurodevelopmental abnormalities, as in at least one of the following:

- decreased cranial size at birth

- structural brain abnormalities (e.g., microcephaly, partial or complete agenesis of the corpus callosum, cerebellar hypoplasia)

- neurologic hard or soft signs (as age appropriate), such as impaired fine motor skills, neurosensory hearing loss, poor tandem gait, poor eye-hand coordination

2. FAS without confirmed maternal alcohol exposure

$\mathrm{B}, \mathrm{C}$, and $\mathrm{D}$ as above

3. Partial FAS with confirmed maternal alcohol exposure

A. Confirmed maternal alcohol exposure*

B. Evidence of some components of the pattern of characteristic facial anomalies

Either $\mathrm{C}$ or $\mathrm{D}$ or $\mathrm{E}$

C. Evidence of growth retardation, as in at least one of the following:

- low birth weight for gestational age

- decelerating weight over time not due to nutrition

- disproportionally low weight-to-height ratio

D. Evidence of CNS neurodevelopmental abnormalities, e.g.,

- decreased cranial size at birth

- structural brain abnormalities (e.g., microcephaly, partial or complete agenesis of the corpus callosum, cerebellar hypoplasia)

- neurologic hard or soft signs (as age appropriate) such as impaired fine motor skills, neurosensory hearing loss, poor tandem gait, poor eye-hand coordination

E. Evidence of a complex pattern of behaviour or cognitive abnormalities that are inconsistent with developmental level and cannot be explained by familial background or environment alone: e.g., learning difficulties; deficits in school performance; poor impulse control; problems in social perception; deficits in higher level receptive and expressive language; poor capacity for abstraction or metacognition; specific deficits in mathematical skills; or problems in memory, attention or judgment. 
a. Presence of 3 characteristic facial features (short palpebral fissures, smooth or flattened philtrum, thin vermilion border).

b. Evidence of significant prenatal exposure to alcohol at levels known to be associated with physical or developmental effects, or both.

c. Presence of 1 or more facial features with growth deficits plus known or probable significant prenatal alcohol exposure.

d. Presence of 1 or more facial features with 1 or more central nervous system deficits plus known or probable significant prenatal alcohol exposure.

e. Presence of 1 or more facial features with pre- or postnatal growth deficits, or both (at the 10th percentile or below [1.5 standard deviations below the mean]) and 1 or more central nervous system deficits plus known or probable significant prenatal alcohol exposure.
1.4 Individuals with learning or behavioural difficulties, or both, without physical or dysmorphic features and without known or likely prenatal alcohol exposure should be assessed by appropriate professionals or specialty clinics (i.e., developmental pediatrics, clinical genetics, psychiatry, psychology) to identify and treat their problems.

\section{Comments}

Screening should not be equated with diagnosis. We know that in some places with no diagnostic services, screening tools have been inappropriately used in lieu of a proper diagnosis. One purpose of screening is to identify and refer pregnant women who may be at risk for an alcohol use disorder and who may place their child at risk for FASD. Several alcohol screening tools have been found to be effective in identifying problem drinking in a primary

\section{Table 1: continued}

\section{Alcohol-related effects}

Clinical conditions in which there is a history of maternal alcohol exposure, ${ }^{*} \dagger$ and where clinical or animal research has linked maternal alcohol ingestion to an observed outcome. There are 2 categories, which may co-occur. If both diagnoses are present, then both diagnoses should be rendered.

4. Alcohol-related birth defects (ARBD)

Congenital anomalies, including malformations and dysplasias

Cardiac

Atrial septal defects

Ventricular septal defects

Aberrant great vessels

Skeletal

Hypoplastic nails

Shortened fifth digits

Radioulnar synostosis

Flexion contractures

Camptodactyly

Tetralogy of Fallot

Renal

Aplastic, dysplastic, hypoplastic kidneys

Clinodactyly

Pectus excavatum and carinatum

Klippel-Feil syndrome

Hemivertebrae

Scoliosis

Horseshoe kidneys

Ureteral duplications

Ocular

Strabismus

Hydronephrosis

Retinal vascular anomalies

Refractive problems secondary to small globes

Auditory

Conductive hearing loss Neurosensory hearing loss

Other

Virtually every malformation has been described in some patient with FAS. The etiologic specificity of most of these anomalies to alcohol teratogenesis remains uncertain.

5. Alcohol-related neurodevelopmental disorder (ARND)

Presence of A or B or both.

A. Evidence of CNS neurodevelopmental abnormalities, as in any one of the following:

- decreased cranial size at birth

- structural brain abnormalities (e.g., microcephaly, partial or complete agenesis of the corpus callosum, cerebellar hypoplasia)

- neurologic hard or soft signs (as age appropriate), such as impaired fine motor skills, neurosensory hearing loss, poor tandem gait, poor eye-hand coordination

B. Evidence of a complex pattern of behaviour or cognitive abnormalities that are inconsistent with developmental level and cannot be explained by familial background or environment alone; e.g., learning difficulties; deficits in school performance; poor impulse control; problems in social perception; deficits in higher level receptive and expressive language; poor capacity for abstraction or metacognition; specific deficits in mathematical skills; or problems in memory, attention or judgment.

*A pattern of excessive intake characterized by substantial, regular intake or heavy episodic drinking. Evidence of this pattern may include frequent episodes of intoxication, development of tolerance or withdrawal, social problems related to drinking, legal problems related to drinking, engaging in physically hazardous behaviour while drinking or alcohol-related medical problems such as hepatic disease.

†As further research is completed and as, or if, lower quantities or variable patterns of alcohol use are associated with ARBD or ARND, these patterns of alcohol use should be incorporated into the diagnostic criteria. 
care setting (e.g., TWEAK, T-ACE, CAGE, AUDIT, SMAST, B-MAST). ${ }^{2,36-38}$

There is moderate evidence ${ }^{37,38}$ to support the use of T-ACE and TWEAK to identify women who would benefit from intervention for alcohol use during pregnancy. If the woman cannot abstain, she should receive support and be referred to appropriate counselling and treatment. Stopping drinking at any point during the pregnancy will improve the outcome for the baby. Research is being carried out to develop gender and culturally appropriate instruments for the screening of all women during their child-bearing years. ${ }^{38}$

The purpose of screening individuals at risk for the effects of prenatal alcohol exposure is to determine whether a pattern of learning and behavioural problems may be related to prenatal alcohol exposure. The screening could be conducted through the education system, the mental health system, the judicial system or social services. The purpose of screening should be to facilitate referral to a diagnostic clinic and highlight the need for referral and support for the birth mother.

The FAS Diagnostic and Prevention Network has had encouraging results in applying the FAS facial photographic screening tool in foster children and school-age children populations. ${ }^{39}$ However, in the wide array of FASDs, facial dysmorphology is often absent and, in the final analysis, has little importance compared with the impact of prenatal alcohol exposure on brain function. However, it is important to note that the facial phenotype is a midline defect that is the most sensitive and specific marker for alcohol-related brain damage.

All those suspected of having brain dysfunction should be referred to an appropriate professional or clinic for assessment (i.e., developmental pediatrics, clinical genetics, psychiatry, psychology). Because of the specificity of FASD clinics in addressing issues related to prenatal alcohol exposure, those with no prenatal alcohol exposure should be referred to an appropriate professional or clinic for assessment, treatment and follow-up.

\section{The physical examination and differential diagnosis}

The purpose of dysmorphology assessment is to identify those with features related to prenatal alcohol exposure and also to identify children with dysmorphic features due to other causes. Occasionally, children with prenatal alcohol effects may have another genetic syndrome as a comorbidity. When in doubt and if feasible, a genetic dysmorphology assesment is advisable.

A general physical and neurologic examination, including appropriate measurements of growth and head size, assessment of characteristic findings and documentation of anomalies (e.g., cleft palate, congenital heart defects, epicanthic folds, high arched palate, poorly aligned or abnormal teeth, hypertelorism, micrognathia, abnormal hair patterning, abnormal palmar creases, skin lesions) is required to exclude the presence of other genetic disorders or multifactorial disorders that could lead to features mimicking FAS or partial FAS (Table 3).

Some children will have significant neurologic deficits, such as deafness, blindness or seizures, and these should be

\begin{tabular}{|c|c|c|c|c|}
\hline Rank & Growth deficiency & FAS facial phenotype & $\begin{array}{l}\text { CNS damage or } \\
\text { dysfunction }\end{array}$ & $\begin{array}{l}\text { Gestational } \\
\text { exposure to } \\
\text { alcohol }\end{array}$ \\
\hline 4 & $\begin{array}{l}\text { Significant } \\
\text { Height and weight } \\
\text { below } 3 \text { rd percentile }\end{array}$ & $\begin{array}{l}\text { Severe } \\
\text { All } 3 \text { features: } \\
\text { PFL } 2 \text { or more SDs } \\
\text { below mean } \\
\text { Thin lip: rank } 4 \text { or } 5 \\
\text { Smooth philtrum: rank } \\
4 \text { or } 5\end{array}$ & $\begin{array}{l}\text { Definite } \\
\text { Structural or } \\
\text { neurologic evidence }\end{array}$ & $\begin{array}{l}\text { High risk } \\
\text { Confirmed } \\
\text { exposure to high } \\
\text { levels }\end{array}$ \\
\hline 3 & $\begin{array}{l}\text { Moderate } \\
\text { Height and weight } \\
\text { below } 10 \text { th percentile }\end{array}$ & $\begin{array}{l}\text { Moderate } \\
\text { Generally } 2 \text { of the } 3 \\
\text { features }\end{array}$ & $\begin{array}{l}\text { Probable } \\
\text { Significant } \\
\text { dysfunction across } 3 \\
\text { or more domains }\end{array}$ & $\begin{array}{l}\text { Some risk } \\
\text { Confirmed } \\
\text { exposure. Level of } \\
\text { exposure unknown } \\
\text { or less than rank } 4\end{array}$ \\
\hline 2 & $\begin{array}{l}\text { Mild } \\
\text { Height or weight } \\
\text { below 10th percentile }\end{array}$ & $\begin{array}{l}\text { Mild } \\
\text { Generally } 1 \text { of the } 3 \\
\text { features }\end{array}$ & $\begin{array}{l}\text { Possible } \\
\text { Evidence of } \\
\text { dysfunction, but less } \\
\text { than rank } 3\end{array}$ & $\begin{array}{l}\text { Unknown } \\
\text { Exposure not } \\
\text { confirmed present } \\
\text { or absent }\end{array}$ \\
\hline 1 & $\begin{array}{l}\text { None } \\
\text { Height and weight at } \\
\text { or above 10th } \\
\text { percentile }\end{array}$ & $\begin{array}{l}\text { Absent } \\
\text { None of the } 3 \text { features }\end{array}$ & $\begin{array}{l}\text { Unlikely } \\
\text { No structural, } \\
\text { neurologic or } \\
\text { functional evidence } \\
\text { of impairment }\end{array}$ & $\begin{array}{l}\text { No risk } \\
\text { Confirmed absence } \\
\text { of exposure from } \\
\text { conception to birth }\end{array}$ \\
\hline
\end{tabular}

Note: $\mathrm{PFL}=$ palpebral fissure length; $\mathrm{SD}=$ standard deviation. 
assessed and documented as essential components of the child's profile. These features do not discriminate alcoholexposed from unexposed children. The face of FAS is the result of a specific effect of ethanol teratogenesis altering growth of the midface and brain. Those exposed to other embryotoxic agents may display a similar, but not identical, phenotypic facial development, impaired growth, a higher frequency of anomalies and developmental and behavioural abnormalities (for a review, see Chudley and Longstaffe ${ }^{24}$ ). However, because FAS facial criteria have been restricted to short palpebral fissures, smooth philtrum and thin upper lip, there is far less overlap with the facial phenotypes associated with other syndromes. Knowledge of exposure history will decrease the possibility of misdiagnosing FASD.

Children may be found to need other medical assessments to address co-occurring issues. For example, sleep

\section{Table 3: Syndromes with constellations of features that overlap with those of FAS}

\begin{tabular}{|c|c|c|}
\hline Syndrome & Overlapping features & $\begin{array}{l}\text { Features of this syndrome that } \\
\text { differentiate it from FAS }\end{array}$ \\
\hline Aarskog syndrome & $\begin{array}{l}\text { Widely spaced eyes, small } \\
\text { nose with anteverted nares, } \\
\text { broad philtrum, mid-facial } \\
\text { recession }\end{array}$ & $\begin{array}{l}\text { Round face, downslanted palpebral } \\
\text { fissures, widow's peak, prominent } \\
\text { "lop" ears, specific contracture of } \\
\text { digits on extension. Inherited as an } \\
\text { x-linked trait. Molecular defect } \\
\text { identified. }\end{array}$ \\
\hline $\begin{array}{l}\text { Brachman-deLange or Cornelia } \\
\text { deLange syndrome }\end{array}$ & $\begin{array}{l}\text { Long philtrum, thin } \\
\text { vermilion border of upper } \\
\text { lip, depressed nasal bridge, } \\
\text { anteverted nares, } \\
\text { microcephaly }\end{array}$ & $\begin{array}{l}\text { Single eyebrow across eyes and } \\
\text { forehead (synophrys), long eyelashes, } \\
\text { downturned corners of mouth, short } \\
\text { upper limbs particularly involving } \\
\text { ulnar side, very short stature. } \\
\text { Molecular defect identified. }\end{array}$ \\
\hline Dubowitz syndrome & $\begin{array}{l}\text { Short palpebral fissures, } \\
\text { widely-spaced eyes, } \\
\text { epicanthal folds, variable } \\
\text { ptosis (droopy eyes) and } \\
\text { blepharophimosis, } \\
\text { microcephaly }\end{array}$ & $\begin{array}{l}\text { Shallow suprorbital ridges, broad } \\
\text { nasal tip, clinodactyly }\end{array}$ \\
\hline $\begin{array}{l}\text { Fetal anticonvulsant syndrome } \\
\text { (includes fetal hydantoin and } \\
\text { fetal valproate syndromes) }\end{array}$ & $\begin{array}{l}\text { Widely-spaced eyes, } \\
\text { depressed nasal bridge, } \\
\text { mid-facial recession, } \\
\text { epicanthal folds, long } \\
\text { philtrum, thin vermilion } \\
\text { border of upper lip }\end{array}$ & $\begin{array}{l}\text { Bowed upper lip, high forehead, small } \\
\text { mouth }\end{array}$ \\
\hline $\begin{array}{l}\text { Maternal phenylketonuria (PKU) } \\
\text { fetal effects }\end{array}$ & $\begin{array}{l}\text { Epicanthal folds, short } \\
\text { palpebral fissures, long } \\
\text { poorly formed philtrum, } \\
\text { thin vermilion border of } \\
\text { upper lip, microcephaly }\end{array}$ & $\begin{array}{l}\text { Prominent glabella, small up turned } \\
\text { nose, round face }\end{array}$ \\
\hline Noonan syndrome & $\begin{array}{l}\text { Low nasal bridge, } \\
\text { epicanthal folds, wide } \\
\text { spaced eyes, long philtrum }\end{array}$ & $\begin{array}{l}\text { Down-slanted palpebral fissures, wide } \\
\text { mouth with well-formed philtrum, } \\
\text { protruding upper lip. Molecular defect } \\
\text { identified. }\end{array}$ \\
\hline Toluene embryopathy & $\begin{array}{l}\text { Short palpebral fissures, } \\
\text { mid face hypoplasia, } \\
\text { smooth philtrum, thin } \\
\text { vermilion border upper lip, } \\
\text { microcephaly }\end{array}$ & $\begin{array}{l}\text { Large anterior fontanelle, hair } \\
\text { patterning abnormalities, ear } \\
\text { anomalies }\end{array}$ \\
\hline Williams syndrome & $\begin{array}{l}\text { Short palpebral fissures, } \\
\text { anteverted nares, broad } \\
\text { long philtrum, maxillary } \\
\text { hypoplasia, depressed nasal } \\
\text { bridge, epicanthic folds, } \\
\text { microcephaly }\end{array}$ & $\begin{array}{l}\text { Wide mouth with full lips and pouting } \\
\text { lower lip, stellate pattern of iris, } \\
\text { periorbital fullness, connective tissue } \\
\text { dysplasia, specific cardiac defect of } \\
\text { suprvalvar aortic stenosis in many. } \\
\text { Chromosome deletion on FISH } \\
\text { (fluorescent in situ hybridization) } \\
\text { probe analysis of } 7 q \text {. }\end{array}$ \\
\hline $\begin{array}{l}\text { Other chromosome deletion and } \\
\text { duplication syndromes }\end{array}$ & $\begin{array}{l}\text { Many have short palpebral } \\
\text { fissures, mid-facial } \\
\text { hypoplasia, smooth } \\
\text { philtrum. }\end{array}$ & $\begin{array}{l}\text { Chromosomal analysis by standard } \\
\text { analysis and some select syndromes } \\
\text { by specific FISH probe analysis }\end{array}$ \\
\hline
\end{tabular}


disturbance is common with prenatal alcohol exposure and medical problems related to obstructive sleep apnea may have been overlooked previously. Atypical seizures may also be present and endocrinopathies may exist as a comorbid reason for growth deficiency. These individuals should be assessed by appropriate health professionals.

\section{2a. Growth}

\section{Recommendations}

2.1 Growth should be monitored to detect deficiency. Presence of pre- or post-natal growth deficiency, defined as height or weight at or below the 10th percentile (1.5 standard deviations below the mean) or a disproportionately low weight-to-height ratio (at or below the 10th percentile) using appropriate norms. To determine that a child is growth deficient requires taking into consideration confounding variables such as parental size, genetic potential and associated conditions (e.g., gestational diabetes, nutritional status, illness).

\section{Comments}

Children affected by prenatal alcohol exposure may have prenatal or postnatal growth deficits. They can be small for gestational age in utero and remain below average throughout their lives with respect to head circumference, weight and height. Many children can have normal growth parameters, but be at risk in later development for clinically significant learning, behavioural and cognitive deficits. If there is no alcohol exposure in the third trimester, the growth parameters can be normal. Gestational diabetes can lead to increased fetal size, which can mask the effects of growth retardation from prenatal alcohol exposure. Furthermore, if the infant is born into a family or a community where "normal" size is above the average for the general population, growth impairment may be masked if the child is compared with standard growth parameters rather than community norms. ${ }^{14}$ Growth deficiencies may not persist with age, and infant growth records may not be available for adults coming in for assessment for the first time. There is a need to establish growth norms for the Canadian population and subpopulations that differ from the general population.

\section{2b. Facial features}

\section{Recommendations}

2.2 The 3 characteristic facial features that discriminate individuals with and without FAS are:

- Short palpebral fissures, at or below the 3rd percentile (2 standard deviations below the mean).

- Smooth or flattened philtrum, 4 or 5 on the 5-point Likert scale of the lip-philtrum guide..$^{25,39}$
- Thin vermilion border of the upper lip, 4 or 5 on the 5-point Likert scale of the lip-philtrum guide.

2.3 Associated physical features (abnormalities such as midface hypoplasia, micrognathia, abnormal position or formation of the ears, high arched palate, hypertelorism, epicanthic folds, limb and palmar crease abnormalities and short-upturned nose) should be recorded but do not contribute to establishing the diagnosis.

2.4 Facial features should be measured in all age groups. If a patient's facial features change with age, the diagnosis of the facial features should be based on the point in time when the features were most severely expressed. When diagnosing adults, it can be helpful to view childhood photographs.

\section{Comments}

A characteristic craniofacial profile associated with FAS was first described by Jones and Smith ${ }^{40}$ in 1975 and later refined by Astley, Clarren and others. ${ }^{25,32,39}$ Individuals with FAS have short palpebral fissures, a thin upper lip and an

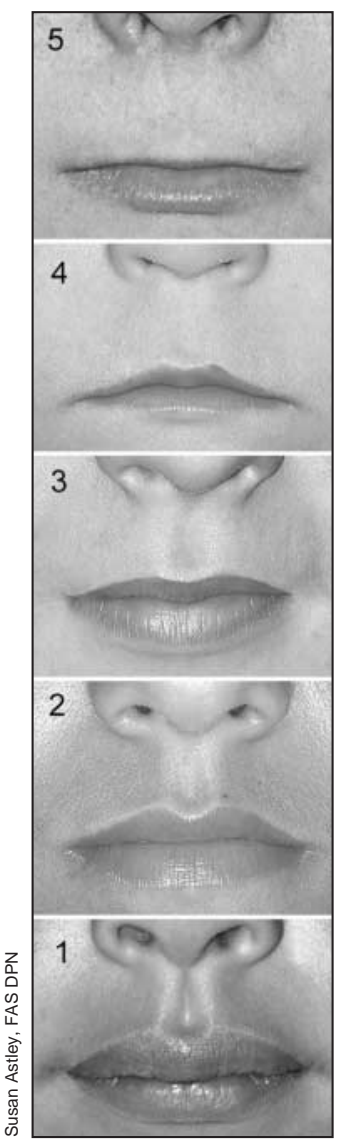

Fig. 1: Lip-philtrum guide. A 5-point pictorial scale for measuring philtrum smoothness and upper lip thinness. Features are measured independently; for example, an individual can have a rank 5 philtrum and a rank 1 upper lip. 
indistinct philtrum (Fig. 1). Palpebral fissure length, philtrum and upper lip differ with race and age. Growth and facial anthropometric data are needed for the specific population, as sensitivity and specificity of the assessment will be lowered without the use of appropriate norms. Some discriminating characteristic features in FAS (i.e., upper lip or philtrum) may become less recognizable with age, making accurate diagnosis more difficult in older groups, but facial features should always be measured. More longitudinal research is needed to correlate changes in these characteristic physical findings in adolescents and adults diagnosed with FAS or partial FAS.

Palpebral fissure length (Fig. 2) is difficult to measure accurately without training. Thomas and co-workers ${ }^{41}$ have published norms for palpebral fissure length at 29 weeks gestation to 14 years. There are a number of opinions about which norms are appropriate, ${ }^{41-44}$ but it is generally agreed that all are flawed in some respect.

Two graphs of palpebral fissure length are presented in Appendix 2. Some discrepancies exist. Both studies used North American white subjects; standards for other populations in Canada are not currently available. Appendix 2-1 may be more reliable when measuring palpebral fissure length using a plastic ruler (in the experience of one of the authors); Appendix 2-2 may be more reliable if slide calipers are used (in the experience of one of the authors). Percentile ranks for both graphs seem to be in agreement until age 7 years, after which Appendix 2-2 shows longer palpebral fissures in older children and adolescents than Appendix 2-1. We believe this may be due to differences in measurement technique. Because calipers are not a common tool in most medical clinics, we recommend the use of a clear flexible plastic ruler.

There is a need to establish updated norms for all ages and subpopulations. Astley and Clarren ${ }^{25,39}$ have developed norms for the assessment of the lip and philtrum using their pictorial guide. Lip-philtrum guides were developed for use in Caucasian and African-American populations, but no standards are currently available for other populations.

\section{Neurobehavioural assessment}

\section{Recommendations}

3.1 The following domains should be assessed:

a. Hard and soft neurologic signs (including sensorymotor signs).

b. Brain structure (occipitofrontal circumference, magnetic resonance imaging, etc.).

c. Cognition (IQ).

d. Communication: receptive and expressive.

e. Academic achievement.

f. Memory.

g. Executive functioning and abstract reasoning.

h. Attention deficit/hyperactivity. i. Adaptive behaviour, social skills, social communication.

3.2 The assessment should include and compare basic and complex tasks in each domain, as appropriate.

3.3 The domains should be assessed as though they were independent entities, but where there is overlap experienced clinical judgment is required to decide how many domains are affected.

3.4 A domain is considered "impaired" when on a standardized measure:

a. Scores are 2 standard deviations or more below the mean, or

b. There is a discrepancy of at least 1 standard deviation between subdomains. For example:

i. Verbal v. non-verbal ability on standard IQ tests, ii. Expressive v. receptive language,

iii. Verbal v. visual memory, or

c. There is a discrepancy of at least 1.5-2 standard deviations among subtests on a measure, taking into account the reliability of the specific measure and normal variability in the population.

3.5 In areas where standardized measurements are not available, a clinical judgment of "significant dysfunction" is made, taking into consideration that important variables, including the child's age, mental health factors, socioeconomic factors and disrupted family or home environment (e.g., multiple foster placements, history of abuse and neglect), may affect development but do not indicate brain damage.

3.6 Evidence of impairment in 3 domains is necessary for a diagnosis, but a comprehensive assessment requires that each domain be assessed to identify strengths and weaknesses.

3.7 The diagnosis should be deferred for some at-risk children (e.g., preschool-age) who have been exposed to al-

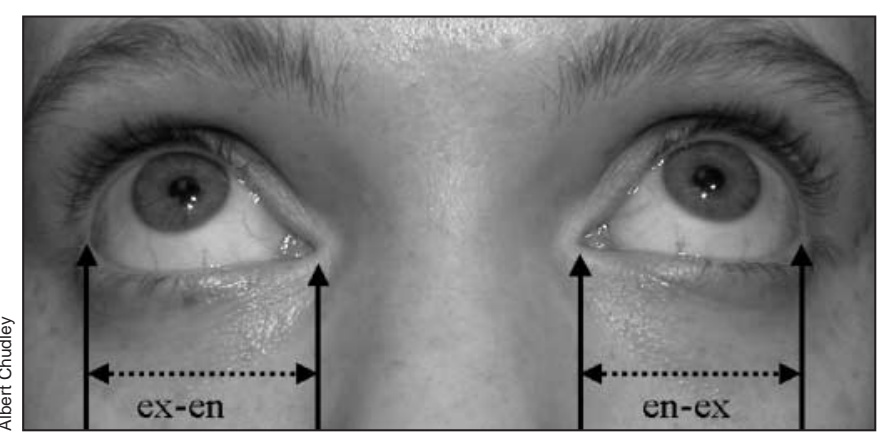

Fig. 2: Palpebral fissure length. To measure palpebral fissure length, identify the inner corner or encanthion (en) and outer corner or excanthion (ex) for each eye. Have the patient look up so that ex can be seen clearly. With a clear flexible ruler held in the horizontal plane, measure the length of each ex-en interval immediately below the eye, being careful not to touch the eye or eyelashes. Plot the result on an appropriate nomogram chart to determine the percentile or standard deviation for each eye. 
cohol but may not yet demonstrate measurable deficits in the brain domains or may be too young to be tested in all the domains. However, developmental assessment should identify areas for early intervention.

Examples of tests that are most widely used to assess the domains and their criteria are provided in Appendix 3.

\section{Comments}

Research reports have documented a range of cognitive and behavioural outcomes associated with prenatal alcohol exposure. Contemporary studies have reported some of these outcomes in the absence of FAS physical features. Currently, no modal profile of abilities has been found to be unique to alcohol exposure, is observed in all those with prenatal alcohol exposure, or can be distinguished from that observed with some other neurobehavioural disorders. Furthermore, not every deficit that we may identify in a child with prenatal exposure to alcohol may be solely the result of alcohol exposure. An expert analysis of neurodevelopmental deficits caused by a range of teratogens and congenital disorders failed to result in a consensus on core deficits associated only with FASD. ${ }^{4}$

Research and experience has shown that features of FASD are complex and multifaceted, originating with organic brain damage caused by alcohol, but interacting with genetic and other influences. Over the lifespan of the affected person, these features may be exacerbated or mitigated by environmental experiences.

To make the diagnosis of FAS, features such as microcephaly, structural abnormalities (as may be detected on brain scans) and hard neurologic signs are taken as strong evidence of organic brain damage. We believe that low-average to borderline intelligence and soft neurologic signs alone are insufficient evidence of brain damage because they are frequently found in the general population. Features such as learning difficulties, attention deficit/hyperactivity disorder and deficits in adaptive skills, memory, higher-level language and abstract thinking are frequently seen in children with prenatal alcohol exposure, but also among those with other etiologies. These deficits can be multifactorial in etiology and can also be attributed to genetics or postnatal experiences.

The 4-Digit Diagnostic Code evaluation of the FASD brain is based on levels of certainty, in the judgement of the clinician, that the individual's cognitive and behavioural problems reflect brain damage. A higher rating may reflect a more severe expression of functional disability, asynchronous patterns across domains or certainty based on deficits in multiple domains. The determination is based on objective evidence of "substantial deficiencies or discrepancies across multiple areas of brain performance." ${ }^{\prime 25,39}$

The $\mathrm{IOM}^{4}$ also requires "evidence of a complex pattern of behavior or cognitive abnormalities that are inconsistent with developmental level and cannot be explained by famil- ial background or environment alone, such as learning difficulties; deficits in school performance; poor impulse control; problems in social perception; deficits in higher level receptive and expressive language; poor capacity for abstraction or metacognition; specific deficits in mathematical skills; or problems in memory, attention, or judgment," but is much less specific than the 4-Digit Diagnostic Code with regard to the criteria for determining the deficit.

We have adapted the method of the 4-Digit Diagnostic Code with regard to identifying domains and severity of impairment or certainty of brain damage. Current research shows overlap between the neurobehavioural outcomes in FAS and ARND diagnostic groups when neuropsychologic data are compared. ${ }^{45}$ In addition, we believe that a single feature such as microcephaly is not a sufficient indicator of brain damage for the purposes of an FAS diagnosis because it may reflect genetic or ethnic differences not reflected in currently available physical norms. Our concern is that there may be an over-diagnosis of FAS if evidence of brain damage is based on a single indicator as allowed by both the 4-Digit Diagnostic Code and the IOM models. An individual showing hard neurologic signs or structural brain abnormalities (i.e., true brain damage) will likely show additional functional deficits in the listed domains. A diagnosis of full FAS will not be denied by combining the criteria for full FAS and ARND in this harmonized system.

Although the domains are considered to be separate and independent entities, there is obviously overlap. For example, a discrepancy between verbal and non-verbal scores on an IQ test (taking into account normal variability in the population) may be reflecting a specific language disability. If language is deficient, can deficits in verbal memory be considered an additional domain? Does a language deficit represent brain damage if the child has experienced a prolonged period of social deprivation? The cut-off of 2 standard deviations below the mean on standardized tests is recommended to increase confidence that abilities in the domain are impaired as a result of brain damage and are scored as "3" (significant dysfunction) on the 4-Digit Diagnostic Code. With 3 such domains, the brain rank is 3: "probable brain dysfunction."

We realize that in standard neuropsychologic practice, 1.5 standard deviations below the mean may indicate subtle impairments. Using the 4-Digit Diagnostic Code, the domains would be scored as "moderate dysfunction" and may result in a brain rank of 2: "possible brain dysfunction." These more subtle findings are an important part of the individual's profile. For the purpose of diagnosis, however, and the certainty that the scores represent injury caused by alcohol, the more extreme cut-off is recommended. The multidisciplinary team, reviewing the data and using experienced clinical judgement, is critical in making an accurate diagnosis as qualitative aspects of performance are also important. The diagnostic profile is dynamic and may change over time; thus individuals affected or suspected to be affected may require several assessments over time. Services should not be based on the diagnosis itself, but rather on the profile of brain function-dysfunction. 


\section{Treatment and follow-up}

\section{Recommendations}

4.1 Education of the patient and family members on features of FASD is crucial. The potential psychosocial tensions that might be expected to develop within the family as a result of the diagnosis should also be discussed. This must be done in a culturally sensitive manner using appropriate language.

4.2 A member of the diagnostic team should follow-up outcomes of diagnostic assessments and treatment plans within a reasonable length of time to assure that the recommendations have been addressed.

4.3 Diagnosed individuals and their families should be linked to resources and services that will improve outcome. However, where services are limited in the community, an individual should not be denied an assessment for diagnosis and treatment. Often the diagnosis in the individual is the impetus that leads to the development of resources.

\section{Maternal alcohol history in pregnancy}

\section{Recommendations}

5.1 Prenatal alcohol exposure requires confirmation of alcohol consumption by the mother during the index pregnancy based on reliable clinical observation, selfreport, reports by a reliable source or medical records documenting positive blood alcohol, alcohol treatment or other social, legal or medical problems related to drinking during the pregnancy.

5.2 The number and type(s) of alcoholic beverages consumed (dose), the pattern of drinking and the frequency of drinking should all be documented if available.

5.3 Hearsay, lifestyle, other drug use or history of alcohol exposure in previous pregnancies cannot, in isolation, be informative of drinking patterns in the index pregnancy. However, co-occurring disorders, significant psychosocial stressors and prenatal exposure to other substances (e.g., smoking, licit or illicit drugs) in the index and previous pregnancies should still be recorded, based on known interactive effects of these variables on the severity of pregnancy outcomes for both the mother and her offspring.

\section{Comments}

Gathering reliable information about maternal drinking is key to establishing an accurate diagnosis. Special attention must be paid to inquiring about maternal alcohol use before the woman recognized that she was pregnant. Some women do not consider that their prior drinking is important and many underreport it. Training is required in how to obtain this information in a non-threatening, nonjudgmental way.

Canadian survey data suggest that the number of women who report drinking during pregnancy has decreased. The National Population Health Survey, 1994-1995 ${ }^{46}$ and National Longitudinal Survey of Children and Youth, 1994-1995 ${ }^{47}$ reported that $17-25 \%$ of women drank alcohol at some point during their pregnancy and 7-9\% drank alcohol throughout their pregnancy. According to the National Longitudinal Survey of Children and Youth, 1998-1999 $14.4 \%$ of women drank at some point during their pregnancy and $4.9 \%$ drank throughout their entire pregnancy (3\% reported binge drinking during pregnancy). In the Fall 2002 Survey of First Nations People Living on Reserve, ${ }^{49} 53 \%$ of the respondents said that cutting down or stopping alcohol use was important for women to have a healthy baby.

The evaluation of "significant alcohol exposure" is often confusing. The IOM describes significant alcohol exposure as "a pattern of excessive intake characterized by substantial, regular intake or heavy episodic drinking"4 (the National Institute on Alcohol, Alcoholism, and Alcohol Abuse defines heavy alcohol use as drinking 5 or more drinks per occasion on 5 or more days in the past 30 days $^{36}$ ). Evidence of this pattern may include frequent episodes of intoxication, development of tolerance or withdrawal, social problems related to drinking, legal problems related to drinking, engaging in physically hazardous behaviour while drinking, or alcohol-related medical problems such as hepatic disease. As further research is completed and as, or if, lower quantities or variable patterns of alcohol use are associated with alcohol-related birth defects (ARBD) or ARND, these patterns of alcohol use should be incorporated into the diagnostic criteria. ${ }^{4}$

\section{Diagnostic criteria for FAS, partial FAS and ARND}

\section{Recommendations}

6.1 The criteria for the diagnosis of fetal alcohol syndrome, after excluding other diagnoses, are:

A. Evidence of prenatal or postnatal growth impairment, as in at least 1 of the following:

a. Birth weight or birth length at or below the 10th percentile for gestational age.

b. Height or weight at or below the 10th percentile for age.

c. Disproportionately low weight-to-height ratio (= 10th percentile).

B. Simultaneous presentation of all 3 of the following facial anomalies at any age:

a. Short palpebral fissure length (2 or more standard deviations below the mean).

b. Smooth or flattened philtrum (rank 4 or 5 on the lip-philtrum guide). 
c. Thin upper lip (rank 4 or 5 on the lip-philtrum guide).

C. Evidence of impairment in 3 or more of the following central nervous system domains: hard and soft neurologic signs; brain structure; cognition; communication; academic achievement; memory; executive functioning and abstract reasoning; attention deficit/hyperactivity; adaptive behaviour, social skills, social communication.

D. Confirmed (or unconfirmed) maternal alcohol exposure.

6.2 The diagnostic criteria for partial fetal alcohol syndrome, after excluding other diagnoses, are:

A. Simultaneous presentation of 2 of the following facial anomalies at any age:

a. Short palpebral fissure length (2 or more standard deviations below the mean).

b. Smooth or flattened philtrum (rank 4 or 5 on the lip-philtrum guide).

c. Thin upper lip (rank 4 or 5 on the lip-philtrum guide).

B. Evidence of impairment in 3 or more of the following central nervous system domains: hard and soft neurologic signs; brain structure; cognition; communication; academic achievement; memory; executive functioning and abstract reasoning; attention deficit/hyperactivity; adaptive behaviour, social skills, social communication.

C. Confirmed maternal alcohol exposure.

6.3 The diagnostic criteria for alcohol-related neurodevelopmental disorder, after excluding other diagnoses, are:

A. Evidence of impairment in 3 or more of the following central nervous system domains: hard and soft neurologic signs; brain structure; cognition; communication; academic achievement; memory; executive functioning and abstract reasoning; attention deficit/hyperactivity; adaptive behaviour, social skills, social communication.

B. Confirmed maternal alcohol exposure.

6.4 The term alcohol-related birth defects (ARBD) should not be used as an umbrella or diagnostic term, for the spectrum of alcohol effects. ARBD constitutes a list of congenital anomalies, including malformations and dysplasias and should be used with caution (Table 1).

\section{Comments}

Our definition of partial FAS differs from the published IOM criteria. ${ }^{4}$ Where significant prenatal alcohol exposure is known and there is significant growth retardation and significant indicative facial features but no evidence of brain involvement, a diagnosis of partial FAS could be made using the IOM criteria. It is our view that, using the term partial FAS in the absence of measurable brain deficits could be harmful for the individual because the diagnosis of partial FAS implies brain dysfunction. If some characteristic facial features and growth impairment, without significant developmental or behavioural problems, are found in children under 6 years of age, it would be prudent to say that the child may be at risk of learning and behaviour problems at a later time due to prenatal alcohol exposure. No alcohol-related diagnosis should be made, but the child must be monitored by the family physician or health care worker and deficits should be documented using a neurodevelopmental assessment.

The term "partial" in partial FAS does not imply that these individuals are less severely impaired in day-to-day functioning than those with a diagnosis of FAS, as the deficits in brain function may be similar.

\section{Harmonization of the Institute of Medicine (IOM) and 4-Digit Diagnostic Code approaches}

\section{Recommendations}

7.1 The approach identified in the 4-Digit Diagnostic Code should be used to describe, assess and measure objectively alcohol exposure, growth, facial features and brain damage. The 4-Digit Diagnostic Code should be recorded for each assessment and may be useful for surveillance and research purposes.

7.2 The terminology in the IOM criteria should be used to describe the diagnosis.

\section{Comments}

Table 4 and Table 5 illustrate how we recommend harmonizing the IOM and 4-Digit Diagnostic Code criteria. The ARBD category has limited utility in the diagnosis, but we do recognize that alcohol is teratogenic and may be responsible for birth defects if exposure occurs during critical periods of development. However, in the absence of other features of FAS or brain deficits, it is difficult to attribute causation.

\section{Future research related to diagnostic guidelines}

The lack or unavailability of evidence and data in key areas limits the effectiveness of the diagnostic process, in general. Such key areas include the development of Canadian growth and anthropometric norms for all ages and ethno-cultural groups. There is also a need for the development and validation of screening tools that are specific and sensitive to prenatal alcohol exposure. These tools should be adaptable for use in various contexts, they should be culturally appropriate and they should lead to accurate referrals for diagnosis and assessment. 


\section{Emerging issues}

\section{Biomarkers}

Often, women will not accurately recall the amount or frequency of alcohol consumption during pregnancy. Some women may also underestimate consumption level or deny that they drank alcohol during pregnancy. Medical records are known to be incomplete with respect to maternal alcohol history. Currently, there are no reliable means to confirm maternal drinking using biochemical markers in pregnancy. High levels of whole blood-associated acetaldehyde, carbohydrate-deficient transferrin, gamma-glutamyl transpeptidase and mean red blood cell volume may be useful markers in pregnant women. ${ }^{50}$

Studies are underway to determine the utility of fatty acid ethyl esters in meconium as markers for prenatal exposure to alcohol. ${ }^{51-53}$ This marker will only be useful if it can be established that fatty acid ethyl ester levels in meconium are predictive of developmental outcome. Meconium testing could alert caregivers to infants who might be at risk for alcohol effects and lead to appropriate monitoring, intervention and prevention. Ethical issues regarding informed consent surround the use of biological markers in the baby that may indicate maternal drinking.

Recent innovations have led to the development of laser surface scanning, a non-invasive method for acquiring 3-dimensional images. ${ }^{33,34}$ This technique is promising in the analysis of facial features associated with prenatal alcohol exposure, but, at present, is a research tool only.

\section{Remote and rural areas}

The availability of diagnostic services is limited in rural and remote areas. A community may not have access to a diagnostic team or resources and services. Until regionally based diagnostic teams are established, the use of telemedicine for distant diagnosis, consultation and training may be helpful. ${ }^{31}$ Recent advances using digital imag- ing and computer-assisted analysis for the diagnosis of characteristic features of FAS have shown promise for analysis of facial features associated with prenatal alcohol exposure. $^{32,33,44}$

Table 5: Comparison of Institute of Medicine (IOM) and 4-Digit Diagnostic Code methods in the diagnosis of FAS

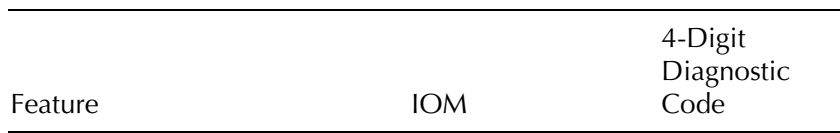

Facial characteristics

Number of features required

Thin (flat) upper lip

Flattened philtrum

Flat midface

Short palpebral fissures

Other features

$\begin{array}{ll}\text { Not specified } & 3 \text { of } 3 \\ \text { Yes } & \text { Yes } \\ \text { Yes } & \text { Yes } \\ \text { Yes } & \text { No } \\ \text { Yes } & \text { Yes } \\ ? & \text { No }\end{array}$

\section{Growth}

Number of features required

Low birth weight alone

Decelerating weight over time

Low weight-to-height ratio

Low height and low weight

1

Yes, percentile

not specified

Yes No

Yes No

No Yes, $\leq 10$ th

percentile

Central nervous system dysfunction

Number of features required 1 structural or $\quad 1$ structural or neurologic feature neurologic

feature

OR

3 domains of significant impairment in function

Structural features may include:

Yes, percentile $\quad$ Yes, $\leq 3 \mathrm{rd}$

Structural abnormalities not specified percentile

Hard neurologic signs

Yes

Yes

Soft neurologic signs

Yes

Yes

No

Table 4: Harmonization of Institute of Medicine (IOM) nomenclature and 4-digit diagnostic code ranks for growth, face, brain and alcohol history

\begin{tabular}{|c|c|c|c|c|}
\hline \multirow[b]{2}{*}{ IOM nomenclature } & \multicolumn{4}{|c|}{ 4-digit diagnostic code ranks } \\
\hline & $\begin{array}{l}\text { Growth } \\
\text { deficiency }\end{array}$ & $\begin{array}{l}\text { FAS facial } \\
\text { phenotype }\end{array}$ & $\begin{array}{l}\text { CNS damage or } \\
\text { dysfunction }\end{array}$ & $\begin{array}{l}\text { Gestational } \\
\text { exposure to } \\
\text { alcohol }\end{array}$ \\
\hline FAS (with confirmed exposure) & 2,3 or 4 & 3 or 4 & 3 or 4 & 3 or 4 \\
\hline FAS (without confirmed exposure) & 2,3 or 4 & 3 or 4 & 3 or 4 & 2 \\
\hline $\begin{array}{l}\text { Partial FAS (with confirmed } \\
\text { exposure)* }\end{array}$ & $1,2,3$ or 4 & 2,3 or 4 & 3 or 4 & 3 or 4 \\
\hline ARND (with confirmed exposure) & $1,2,3$ or 4 & 1 or 2 & $\begin{array}{l}3 \text { or } 4 \\
(2 \text { for }<6 \text { years })\end{array}$ & 3 or 4 \\
\hline
\end{tabular}

Note: $\mathrm{ARND}=$ alcohol-related neurodevelopmental disorder; $\mathrm{CNS}=$ central nervous system; $\mathrm{FAS}$ = fetal alcohol syndrome. Source: Developed by Kwadwo Asante and Julianne Conry

*Any final 4-digit code that can be made with these combinations of numbers and that is not also an FAS code signifies partial FAS. Combinations of face 2 that include two significant facial features also meet criteria for partial FAS. 


\section{Adult diagnosis}

Diagnosis of adults creates special challenges in all aspects of the diagnosis. Physical features may change over time, there may be catch-up growth, and cumulative environmental influences may distort the evaluation of brain function. The adult's history may include additional traumatic head injury, alcohol and drug abuse, and mental health problems. Although tests for the various domains are readily available, clinicians working with the adult FASD population find that the tests are often not sensitive to real-life issues. In addition to the data required for the diagnosis, an assessment must include additional components such as functional literacy and numeracy, employability and quality of life, which fall within the domain of adaptive skills. The clinician should not rely solely on the self-report of the individual who is alcohol-affected; the history and abilities of the individual must be verified by a reliable source.

\section{Conclusion}

The assessment for prenatal alcohol exposure is a diagnosis for the affected person, the birth mother and possibly affected siblings. Rather than labeling, a diagnosis provides a blueprint for early intervention. Treatment planning and implementation, specifically targeted toward the unique needs of the individual and the family, form a large part of the diagnosis.

These guidelines and recommendations have been developed in parallel and in consultation with a United States committee charged with the same task..$^{54}$ The challenges for prevention and diagnosis of FASD and intervention to assist those affected by this disorder are evolving and dynamic. Research is ongoing to determine whether tools, such as novel brain imaging techniques, biomarkers and DNA micro-array techniques, might enhance accurate and reliable alcohol-related diagnoses and treatment.

We hope that these guidelines and recommendations will be used to facilitate training of health professionals, improve access to diagnostic services and facilitate referral for intervention or treatment for all people and families living with this disability.

\section{This article has been peer reviewed.}

From the Children's Hospital, Health Sciences Centre, Departments of Pediatrics and Child Health and Biochemistry and Medical Genetics, University of Manitoba, Winnipeg, Man. (Chudley); the Department of Educational and Counselling Psychology and Special Education, University of British Columbia; Asante Centre for Fetal Alcohol Syndrome, Maple Ridge, B.C. (Conry); the Department of Obstetrics and Gynecology, University of Ottawa, Ottawa, Ont. (Cook); the Department of Pediatrics, University of British Columbia, BC Children's Hospital, Vancouver, B.C. (Loock); the Provincial Medical Genetics Program; the Department of Pediatrics, Memorial University of Newfoundland, St. John's, Nfld. (Rosales) and the Department of Pediatrics, Georges Dumont Hospital, Moncton, N.B. (LeBlanc).
Contributors: All authors contributed equally to this manuscript. All authors contributed substantially to conception and design, or acquisition of data, or analysis and interpretation of data and drafted the article or revised it critically for important intellectual content. They gave their final approval of the version submitted to be published.

Acknowledgements: This work is supported by the FASD Teams of the Public Health Agency of Canada and the First Nations and Inuit Health Branch, Health Canada. The authors would like to thank the many clinicians and individuals who helped develop, review and provide feedback on these guidelines, especially the Public Health Agency of Canada's National Advisory Committee on FASD; Drs. Fred Boland, Susan Astley and Sterling Clarren; and the Centers for Disease Control and Prevention's scientific working group on diagnosis. This work was supported by the Public Health Agency of Canada and the First Nations and Inuit Health Branch, Health Canada.

\section{References}

1. Jones KL, Smith DW. Recognition of the fetal alcohol syndrome in early infancy. Lancet 1973;2(7836):999-1001.

2. Sokol RJ, Delaney-Black V, Nordstrom B. Fetal alcohol spectrum disorder. 7AMA 2003;290(22):2996-9.

3. Streissguth AP. Fetal alcohol syndrome: a guide for families and communities. Baltimore: Paul H. Brookes; 1997.

4. Stratton K, Howe C, Battaglia FC. Fetal alcohol syndrome: diagnosis, epidemiology, prevention, and treatment. Washington: Institute of Medicine and National Academy Press; 1996. Available: www.nap.edu/books/0309052920/html/index .html (accessed 2004 Oct 29).

5. Streissguth AP. Maternal drinking and the outcome of pregnancy: implications for child mental health. Am $\mathcal{f}$ Orthopsychiatry 1977;47(3):422-31.

6. Joint statement: prevention of fetal alcohol syndrome (FAS) fetal alcohol effects (FAE) in Canada. Ottawa: Health Canada; 1996.

7. Roberts G., Nanson J. Best practices fetal alcohol syndrome/fetal alcohol effects and the effects of other substance use during pregnancy. Ottawa: Health Canada; 2003.

8. Chavez GF, Cordero JF, Becerra JE. Leading major congenital malformations among minority groups in the United States, 1981-1986. MMWR Morb Mortal Wkly Rep 1988;37(3):17-24.

9. Sokol RJ, Clarren SK. Guidelines for use of terminology describing the impact of prenatal alcohol on the offspring. Alcohol Clin Exp Res 1989;13(4):597-8.

10. Sampson PD, Bookstein FL, Barr HM, Streissguth AP. Prenatal alcohol exposure, birthweight, and measures of child size from birth to age 14 years. $\mathrm{Am}$ F Public Health 1994;84(9):1421-8.

11. Sampson PD, Streissguth AP, Bookstein FL, Little RE, Clarren SK, Dehaene $\mathrm{P}$, et al. Incidence of fetal alcohol syndrome and prevalence of alcohol-related neurodevelopmental disorder. Teratology 1997;56(5):317-26.

12. Robinson GC, Conry JL, Conry RF. Clinical profile and prevalence of fetal alcohol syndrome in an isolated community in British Columbia. CMA7 1987; 137(3):203-7.

13. Williams RJ, Odaibo FS, McGee JM. Incidence of fetal alcohol syndrome in northeastern Manitoba. Can 7 Public Health 1999;90(3):192-4.

14. Square D. Fetal alcohol syndrome epidemic on Manitoba reserve. CMAf 1997;157(1):59-60.

15. Asante KO, Nelms-Maztke J. Report on the survey of children with chronic handicaps and fetal alcobol syndrome in the Yukon and Nortbwest British Columbia. Whitehorse: Council for Yukon Indians; 1985.

16. Habbick BF, Nanson JL, Snyder RE, Casey RE, Schulman AL. Foetal alcohol syndrome in Saskatchewan: unchanged incidence in a 20-year period. Can 7 Pub Health 1996;87(3):204-7.

17. Sood B, Delaney-Black V, Covington C, Nordstrom-Klee B, Ager J, Templin T, et al. Prenatal alcohol exposure and childhood behavior at age 6 to 7 years: I. dose-response effect. Pediatrics 2001;108(2):E34.

18. Bingol N, Schuster C, Fuchs M, Iosub S, Turner G, Stone RK, et al. The influence of socioeconomic factors on the occurrence of fetal alcohol syndrome. Adv Alcobol Subst Abuse 1987;6(4):105-18.

19. Astley SJ, Bailey D, Talbot C, Clarren SK. Fetal alcohol syndrome (FAS) primary prevention through FAS diagnosis: I. Identification of high-risk birth mothers through the diagnosis of their children. Alcobol Alcobol 2000;35(5): 499-508.

20. Jacobson JL, Jacobson SW. Prenatal alcohol exposure and neurobehavioral development: where is the threshold? Alcobol Health Res World 1994;18:30-6.

21. Jacobson JL, Jacobson SW. Drinking moderately and pregnancy. Effects on child development. Alcohol Res Health 1999;23(1):25-30.

22. Streissguth A, Barr H, Kogan J, Bookstein F. Primary and secondary disabilities in fetal alcohol syndrome. In: Streissguth AP, Kanter J, editors. The challenge of fetal alcohol syndrome: overcoming secondary disabilities. Seattle: University of Washington Press; 1997. pp 25-39.

23. Astley SJ, Bailey D, Talbot T, Clarren SK. Fetal alcohol syndrome (FAS) primary prevention through FAS diagnosis: II. A comprehensive profile of 80 birth mothers of children with FAS. Alcohol Alcobol 2000;35(5):509-19. 
24. Chudley AE, Longstaffe SE. Fetal alcohol syndrome and fetal alcohol spectrum disorder. In: Cassidy S, Allanson J, editors. Management of genetic syndromes. 2nd ed. New York: John Wiley and Sons; 2004.

25. Astley SJ, Clarren SK. Diagnostic guide for fetal alcohol syndrome and related conditions: the 4-Digit Diagnostic Code. 2nd ed. Seattle: University of Washington Publication Services; 1999.

26. Clarke ME, Tough SC. A national survey regarding knowledge and attitudes of health professionals about fetal alcohol syndrome. Ottawa: Health Canada; 2003.

27. Lemoine P, Harousseau H, Borteyru JP, Menuet JC. Les enfants de parents alcooliques - anomalies observées: à propos de 127 cas. Ouest Med 1968;21:476-82.

28. Jones KL, Smith DW, Ulleland CN, Streissguth AP. Pattern of malformation in offspring of chronic alcoholic mothers. Lancet 1973;1(7815):1267-71.

29. Clarren SK, Smith DW. The fetal alcohol syndrome. Lamp 1978;35(10):4-7.

30. Astley SJ, Clarren SK. Diagnosing the full spectrum of fetal alcohol-exposed individuals: introducing the 4-Digit Diagnostic Code. Alcohol Alcobol 2000;35(4):400-10.

31. Benoit T, Bowes MD, Bowman N, Cantin D, Chudley A, Crolly D, et al Telemedicine diagnosis for fetal alcohol syndrome - the Manitoba experience. Pediatr Child Health 2002;7:147-51.

32. Astley SJ, Stachowiak J, Clarren SK, Clausen C. Application of the fetal alcohol syndrome facial photographic screening tool in a foster care population. 7 Pediatr 2002;141(5):712-7.

33. Astley SJ, Clarren SK. Measuring the facial phenotype of individuals with prenatal alcohol exposure: correlations with brain dysfunction. Alcohol Alcohol 2001;36(2):147-59.

34. Hennessy RJ, Kinsella A, Waddington JL. 3D laser surface scanning and geometric morphometric analysis of craniofacial shape as an index of cerebro-craniofacial morphogenesis: initial application to sexual dimorphism. Biol Psychiatry 2002;51(6):507-14.

35. Da Silveira AC, Daw JL Jr, Kusnoto B, Evans C, Cohen M. Craniofacial applications of three-dimensional laser surface scanning. 7 Craniofac Surg 2003; 14(4);449-56.

36. US Department of Health and Human Services. National Institute on Alcohol Abuse and Alcoholism. 10th special report to the US Congress on alcohol and health: highlights from current research. Washington: The Institute; 2000.

37. Bradley KA, Boyd-Wickizer J, Powell SH, Burman ML. Alcohol screening questionnaires in women: a critical review. FAMA 1998;280(2):166-71.

38. Russell M, Martier SS, Sokol RJ, Mudar P, Bottoms S, Jacobson S, et al. Screening for pregnancy risk-drinking. Alcohol Clin Exp Res 1994;18(5):1156-61.

39. Astley SJ, Clarren SK. A case definition and photographic screening tool for the facial phenotype of fetal alcohol syndrome. F Pediatr 1996;129(1):33-41.

40. Jones KL, Smith DW. The fetal alcohol syndrome. Teratology 1975;12(1):1-10

41. Thomas IT, Gaitantzis YA, Frias JL. Palpebral fissure length from 29 weeks gestation to 14 years. 7 Pediatr $1987 ; 111: 267-8$
42. Hall JG, Froster-Iskenius UG, Allanson JE, editors. Handbook of normal physical measurements. Oxford: Oxford University Press; 1989. pp. 149-50.

43. Farkas LG. Antbropometry of the head and face. 2nd ed. New York: Raven Press; 1994

44. Moore ES, Ward RE, Jamison PL, Morris CA, Bader PI, Hall BD. New perspectives on the face in fetal alcohol syndrome: what anthropometry tells us. Am 7 Med Genet 2002;109(4):249-60.

45. Mattson SN, Riley EP, Gramling L, Delis DC, Jones KL. Heavy prenatal alcohol exposure with or without physical features of fetal alcohol syndrome leads to IQ deficits. 7 Pediatr 1997;131(5):718-21.

46. National population health survey, 1994-1995. Ottawa: Statistics Canada; 1995 Available: stcwww.statcan.ca/english/sdds/5004.htm (accessed 2004 Oct 29).

47. National longitudinal survey of children and youth, 1994-1995. Ottawa: Statistics Canada; 1995

48. National longitudinal survey of children and youth, 1998-1999. Ottawa: Statistics Canada; 1999.

49. Fall 2002 survey of First Nations people living on reserve. Ottawa: EKOS Research; 2002.

50. Stoler JM, Huntington KS, Petersen CM, Daniel P, Aboagye KK, Lieberman $\mathrm{E}$, et al. The prenatal detection of significant alcohol exposure with maternal blood markers. F Pediatr 1998; 133(3):346-52.

51. Moore C, Jones J, Lewis D, Buchi K. Prevalence of fatty acid ethyl esters in meconium specimens. Clin Chem 2003;49(1):133-6.

52. Bearer CF. Meconium as a biological marker of prenatal exposure. Ambul Pediatr 2003;3(1):40-3

53. Chan D, Bar-Oz B, Pellerin B, Paciorek C, Klein J, Kapur B, et al. Population baseline of meconium fatty acid ethyl esters among infants of non-drinking women in Jerusalem and Toronto. Ther Drug Monit 2003;25(3):271-8.

54. National Center on Birth Defects and Developmental Disabilities Centers for Disease Control and Prevention Department of Health and Human Services. Fetal Alcohol Syndrome: Guidelines for Referral and Diagnosis: National Task Force on Fetal Alcohol Syndrome and Fetal Alcohol Effect; 2004 http://www.cdc.gov/ncbddd/fas/documents/FAS_guidelines_accessible.pdf

Correspondence to: Dr. Jocelynn L. Cook, FASD Team, Public Health Agency of Canada, Division of Childhood and Adolescence, Jeanne Mance Bldg. 9th flr, Tunney's Pasture, Address Locator 1909C2, Ottawa ON K1A OK9; jocelynn@primus.ca 


\begin{tabular}{|c|c|c|c|c|}
\hline Participant & City & Province & Profession & \# Consultations \\
\hline Albert Chudley & Winnipeg & Man. & $\begin{array}{l}\text { Physician, Clinic for Drug and Alcohol } \\
\text { Exposed Children }\end{array}$ & 12 \\
\hline Al Kircher & Winnipeg & Man. & Psychologist & 1 \\
\hline Andrea Moser & Ottawa & Ont. & Correctional Services Canada & 1 \\
\hline Anne Fuller & Vancouver & $\mathrm{BC}$ & $\begin{array}{l}\text { BC Ministry of Children and Family } \\
\text { Development }\end{array}$ & 1 \\
\hline Annette Lemire & Edmonton & Alta. & Health and Wellness & 2 \\
\hline Arthur Blue & Brandon & Man. & Native Psychologists in Canada & 1 \\
\hline Ben Giddard & Calgary & Alta. & Physician, Alberta Children's Hospital & 1 \\
\hline Billie Jean Benisty & Ottawa & Ont. & Health Canada & 2 \\
\hline Bob Armstrong & Vancouver & $\mathrm{BC}$ & $\begin{array}{l}\text { Physician, BC Women's and Children's } \\
\text { Hospital }\end{array}$ & 2 \\
\hline Bonnie Baxter & Vancouver & $\mathrm{BC}$ & Speech/Language Pathologist & 1 \\
\hline Brad Bell & Whitehorse & $\mathrm{YT}$ & Health and Social Services & 1 \\
\hline Brian Marder & Edmonton & Alta. & Career Counsellor & 1 \\
\hline Bryce Lark & Whitehorse & YT & Health and Social Services & 1 \\
\hline Carol Gregson & Iqalauit & Nun. & Nunavut Dept of Health & 1 \\
\hline Carol Woodworth & Vancouver & $\mathrm{BC}$ & $\begin{array}{l}\text { Speech/Language Pathologist, Asante } \\
\text { Centre for FAS }\end{array}$ & 1 \\
\hline Cathie Royle & St. John's & Nfld. & $\begin{array}{l}\text { Child Youth and Family Programs, } \\
\text { Dept. Health and Community Services }\end{array}$ & 2 \\
\hline Christine Lilley & Vancouver & $\mathrm{BC}$ & $\begin{array}{l}\text { Psychologist, BC Women's and } \\
\text { Children's Hospital }\end{array}$ & 1 \\
\hline Christine Loock & Vancouver & B.C. & $\begin{array}{l}\text { Physician, BC Women's and Children's } \\
\text { Hospital }\end{array}$ & 11 \\
\hline Claudette Landry & Frederictom & N.B. & $\begin{array}{l}\text { Public Health, Dept. Health and } \\
\text { Wellness }\end{array}$ & 2 \\
\hline Dan Dubovsky & Washington & DC & FAS Specialist, FAS Center of Excellence & 2 \\
\hline $\begin{array}{l}\text { Darlene } \\
\text { MacDonald }\end{array}$ & Ottawa & Ont. & Health Canada & 2 \\
\hline Darren Joslin & Edmonton & Alta. & Health and Wellness & 2 \\
\hline Dawn Ridd & Winnipeg & Man. & Manitoba Health & 1 \\
\hline Del Nyberg & & $\mathrm{BC}$ & BC Health & 2 \\
\hline Diane Fast & Vancouver & $\mathrm{BC}$ & $\begin{array}{l}\text { Psychiatrist, , BC Women's and } \\
\text { Children's Hospital }\end{array}$ & 1 \\
\hline Donna Ludvigsen & Edmonton & Alta. & Health and Wellness & 1 \\
\hline Edward Cross & Kahnawake & Que. & Education Specialist & 2 \\
\hline Elaine Orrbine & Ottawa & Ont. & $\begin{array}{l}\text { Canadian Association of Pediatric } \\
\text { Health Centres, Canadian Pediatric } \\
\text { Chairs }\end{array}$ & 1 \\
\hline Ellen Fantus & Toronto & Ont. & $\begin{array}{l}\text { Psychologist, Toronto Hospital for Sick } \\
\text { Children }\end{array}$ & 1 \\
\hline Faye Brooks & Ottawa & Ont. & Canadian Nurses Association & 1 \\
\hline Faye Stark & $\begin{array}{l}\text { Fort } \\
\text { Providence }\end{array}$ & NWT & Health and Social Services & 1 \\
\hline $\begin{array}{l}\text { Fjola Hart- } \\
\text { Wasekeeiskaw }\end{array}$ & Ottawa & Ont. & $\begin{array}{l}\text { Aboriginal Nurses Association of } \\
\text { Canada }\end{array}$ & 2 \\
\hline Fred Boland & Kingston & Ont. & Psychologist, Queen's University & 6 \\
\hline
\end{tabular}




\begin{tabular}{|c|c|c|c|c|}
\hline \multicolumn{5}{|c|}{ Appendix 1: continued } \\
\hline Gail Andrew & Edmonton & Alta & $\begin{array}{l}\text { Physician, Glenrose Rehabilitation } \\
\text { Hospital }\end{array}$ & 4 \\
\hline Gideon Koren & Toronto & Ont. & $\begin{array}{l}\text { Physician, Toronto Hospital for Sick } \\
\text { Children }\end{array}$ & 6 \\
\hline Graham Robinson & Ottawa & Ont. & RCMP & 1 \\
\hline Guy Burbon & Ottawa & Ont. & Solicitor General & 1 \\
\hline Hasu Rajani & Cold Lake & Alta. & Physician, Lakeland Centre for FAS & 2 \\
\hline Holly Mackay & Ottawa & Ont. & Health Canada & 1 \\
\hline Irena Nulman & Toronto & Ont. & $\begin{array}{l}\text { Physician, Toronto Hospital for Sick } \\
\text { Children }\end{array}$ & 3 \\
\hline Jacquelyn Bertrand & Atlanta & GA & $\begin{array}{l}\text { Psychologist, Centers for Disease Control } \\
\text { and Prevention }\end{array}$ & 1 \\
\hline Jan Lutke & Vancouver & $\mathrm{BC}$ & BC FAS Support Network & 1 \\
\hline Janice Birney & Ottawa & Ont. & Indian and Northern Affairs Canada & 1 \\
\hline Jasjeet Sidhu & Atlanta & GA & $\begin{array}{l}\text { Medical Epidemiologist, Centers for } \\
\text { Disease Control and Prevention }\end{array}$ & 1 \\
\hline Jo Nanson & Saskatoon & Sask. & Psychologist & 4 \\
\hline Joanne Rovet & Toronto & Ont. & $\begin{array}{l}\text { Psychologist, Toronto Hospital for Sick } \\
\text { Children }\end{array}$ & 2 \\
\hline Joanne Weinberg & Vancouver & $\mathrm{BC}$ & Neuroscientist & 1 \\
\hline Jocelynn Cook & Ottawa & Ont. & Health Canada & 11 \\
\hline Jocyline Gauthier & Whitehorse & $\mathrm{YT}$ & Health and Social Services & \\
\hline John Arnett & Winnipeg & Man. & Psychologist & 1 \\
\hline John Godel & $\begin{array}{l}\text { Campbell } \\
\text { River }\end{array}$ & $\mathrm{BC}$ & Physician & 1 \\
\hline John Service & Ottawa & Ont. & Canadian Psychological Society & 1 \\
\hline Julie Conry & Vancouver & $\mathrm{BC}$ & Psychologist, Asante Centre for FAS & 11 \\
\hline Karen Archbell & Toronto & Ont. & Ontario Dept of Health & 1 \\
\hline Kathleen Montpetit & Montreal & Que. & $\begin{array}{l}\text { Occupational Therapist, Shriner's } \\
\text { Hospital }\end{array}$ & 2 \\
\hline Kathleen Montpetit & Montreal & Que. & $\begin{array}{l}\text { Occupational Therapist, Shriner's } \\
\text { Hospital }\end{array}$ & 1 \\
\hline Kathy Horne & Edmonton & Alta. & $\begin{array}{l}\text { Psychologist, Glenrose Rehabilitation } \\
\text { Hospital }\end{array}$ & 1 \\
\hline Kathy Jones & Winnipeg & Man. & $\begin{array}{l}\text { Psychologist, West Region First Nation } \\
\text { Child and Family Centre }\end{array}$ & 1 \\
\hline Kelly Stone & Ottawa & Ont. & Director, Health Canada & 3 \\
\hline Kwadwo Asante & Vancouver & $\mathrm{BC}$ & Physician, Asante Centre for FAS & 4 \\
\hline Leigh Wincott & Thompson & Man. & $\begin{array}{l}\text { Physician, Thompson Diagnostic Clinic } \\
\text { for FAS }\end{array}$ & 2 \\
\hline Leslie Grob & Regina & Sask. & Saskatchewan Health & 2 \\
\hline Margaret Clarke & Calgary & Alta & Physician, Alberta Children's Hospital & 3 \\
\hline Marie Adele Davis & Ottawa & Ont. & Canadian Pediatric Society & 1 \\
\hline Marilou Reeve & Ottawa & Ont. & Youth Justice & 1 \\
\hline $\begin{array}{l}\text { Marilyn Van } \\
\text { Bibber }\end{array}$ & Vancouver & $\mathrm{BC}$ & BC FAS Resource Network & 1 \\
\hline Mary Cox-Millar & Winnipeg & Man. & $\begin{array}{l}\text { Coordinator, Clinic for Drug and Alcohol } \\
\text { Exposed Children }\end{array}$ & 1 \\
\hline $\begin{array}{l}\text { Mary Ellen } \\
\text { Baldwin }\end{array}$ & Calgary & Alta. & Psychologist, Alberta Children's Hospital & 1 \\
\hline Mary Johnston & Ottawa & Ont. & Health Canada & 4 \\
\hline Mary Lynch & Saint John & NB & New Brunswick Family Services & 1 \\
\hline Mercedes Mompel & Toronto & Ont. & Health and Long-term Care & 1 \\
\hline
\end{tabular}




\begin{tabular}{|c|c|c|c|c|}
\hline \multicolumn{5}{|c|}{ Appendix 1: continued } \\
\hline Michelle Dubik & Winnipeg & Man. & Healthy Child Manitoba & 2 \\
\hline Nadine Huggins & Ottawa & Ont. & Health Canada & 3 \\
\hline Nancy Taylor & Halifax & NS & & 1 \\
\hline Nicole Chatel & Yellowknife & NWT & Stanton Territorial Health Authority & 1 \\
\hline Nicole LeBlanc & Moncton & NB & Physician, Georges Dumont Hospital & 5 \\
\hline Nikki Bansil & Ottawa & Ont. & Canadian Medical Association & 1 \\
\hline Pamela Massad & Ottawa & Ont. & Health Canada & 1 \\
\hline Patricia Blakely & Saskatoon & Sask. & Physician, Kinsmen Children's Centre & 4 \\
\hline $\begin{array}{l}\text { Patricia } \\
\text { MacPherson }\end{array}$ & Montague & PEI & $\begin{array}{l}\text { Canadian Correctional Services Research } \\
\text { Centre }\end{array}$ & 1 \\
\hline Pearl Park & Calgary & Alta. & $\begin{array}{l}\text { Speech/Language Pathologist, Alberta } \\
\text { Children's Hospital }\end{array}$ & 1 \\
\hline Peter Waas & LaCombe & Alta & Psychologist & 3 \\
\hline Rachelle Deneault & Whitehorse & $\mathrm{YT}$ & & 1 \\
\hline Richard Snyder & Saskatoon & Sask & Physician, Kinsmen Children's Centre & 1 \\
\hline Roxana Vernescu & St John's & Nfld. & Psychologist, Memorial University & 1 \\
\hline $\begin{array}{l}\text { Samantha } \\
\text { Nadjiwan }\end{array}$ & Ottawa & Ont. & $\begin{array}{l}\text { First Nations Child and Family Caring } \\
\text { Society of Canada }\end{array}$ & 1 \\
\hline Sandy Clarren & Seattle & WA & Psychologist, University of Washington & 1 \\
\hline Sandy Steinwender & Iqualuit & Nun. & Health and Social Services & 1 \\
\hline $\begin{array}{l}\text { Sharon } \\
\text { Bartholomew }\end{array}$ & Ottawa & Ont. & Health Canada & 2 \\
\hline Soo-Hong Uh & Vancouver & $\mathrm{BC}$ & Scientist, BC Vital Statistics & 2 \\
\hline Sterling Clarren & Seattle & WA & Physician, University of Washington & 1 \\
\hline Suzanne Guay & Ottawa & Ont. & National Parole Board & 1 \\
\hline Ted Rosales & St. John's & Nfld. & Physician, Memorial University & 12 \\
\hline Terry Benoit & Winnipeg & Man. & $\begin{array}{l}\text { Physician, Clinic for Drug and Alcohol } \\
\text { Exposed Children }\end{array}$ & 1 \\
\hline Tim Oberlander & Vancouver & $\mathrm{BC}$ & $\begin{array}{l}\text { Physician, BC Women's and Children's } \\
\text { Hospital }\end{array}$ & 1 \\
\hline Val Massey & Edmonton & Alta. & Psychologist, DV Massey and Associates & 1 \\
\hline Valerie Flynn & Ottawa & Ont. & Health Canada & 2 \\
\hline Vyta Senikas & Ottawa & Ont. & $\begin{array}{l}\text { Society of Obstetricians and } \\
\text { Gynecologists of Canada }\end{array}$ & 1 \\
\hline $\begin{array}{l}\text { Wendy Sky } \\
\text { Delaronde }\end{array}$ & Kahnawake & Que. & Nurse & 1 \\
\hline Yaya deAndrade & Vancouver & $\mathrm{BC}$ & $\begin{array}{l}\text { Psychologist, BC Women's and Children's } \\
\text { Hospital }\end{array}$ & 1 \\
\hline Yeshodara Naidoo & Ottawa & Ont. & Health Canada & 1 \\
\hline
\end{tabular}


Appendix 2: Guides for measurement of palpebral fissure length

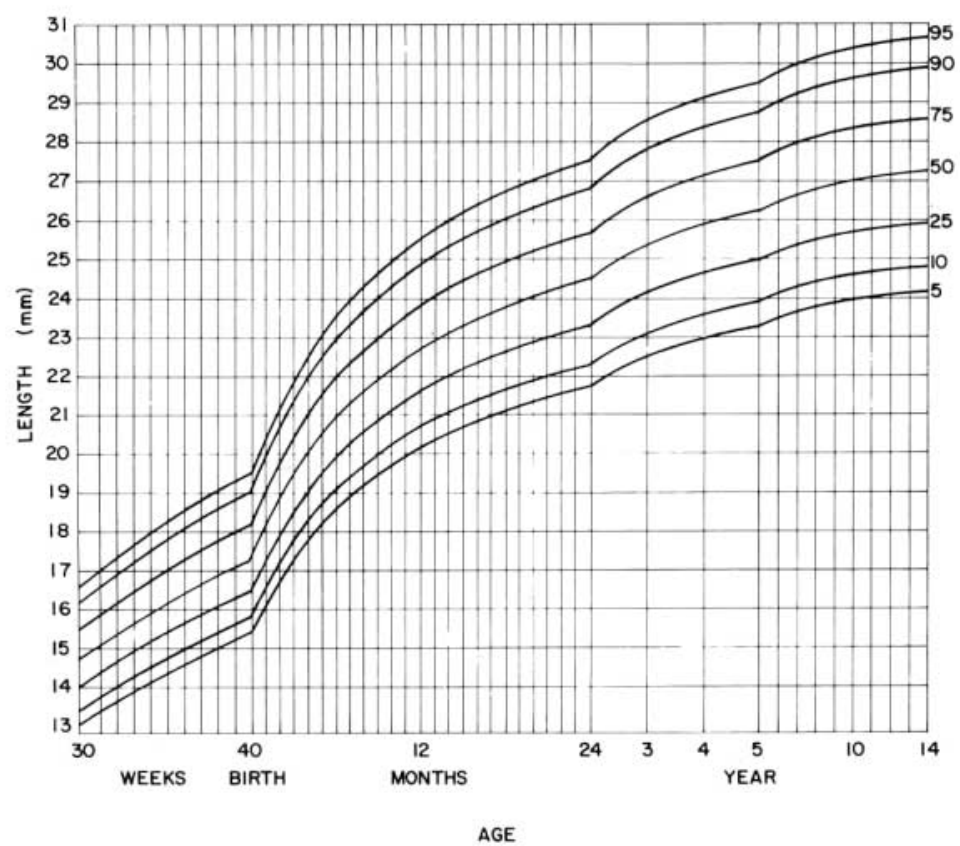

Appendix 2-1: Relation between palpebral fissure length and age in both sexes of American white children aged 29 weeks to 14 years. ${ }^{41}$

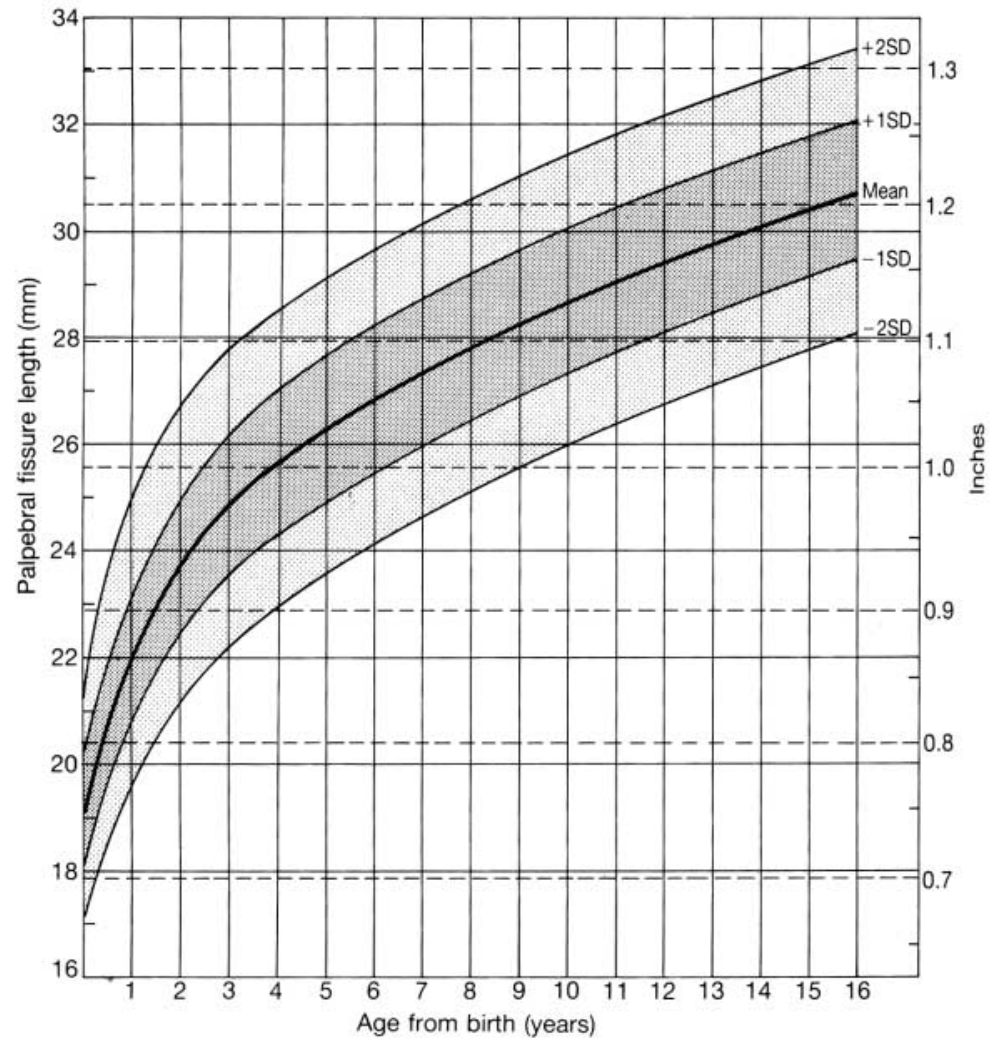

Appendix 2-2: Palpebral fissure length for both sexes, birth to 16 years. $^{42}$ 


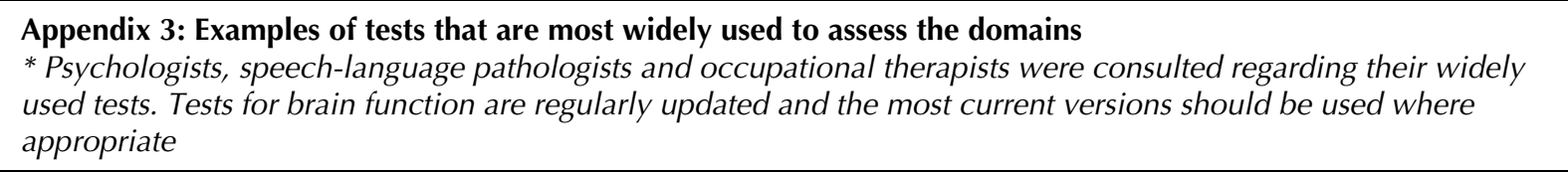

\section{Hard and soft neurologic signs (including sensory-motor}

Hard neurologic signs are assessed by the physician according to usual standards.

Soft neurologic signs include motor signs that can be elicited on the physical examination, with referral for occupational therapy assessment where appropriate.

Tests of motor functioning include:

Movement Assessment Battery for Children

Brunuinks-Oseretsky Scales of Motor Development

Alberta Infant Motor Scale

Peabody Developmental Motor Scales

Quick Neurological Screening Test-II

Tests for visual-motor functioning include:

Developmental Test of Visual-Motor Integration or Bender Gestalt (simple)

Rey Complex Figure Test and Recognition Trial (complex)

Tests of perception include:

Gardner Test of Visual Perceptual Skills

Gardner Test of Auditory Perceptual Skills

Tests of sensory function include:

Dunn Sensory Profile

University of Washington Sensori-motor Checklist

Congenital sensory-neural hearing loss as evaluated by audiologist

Congenital vision anomalies as evaluated by an ophthalmologist

Tests and observations of articulation, phonology and motor speech if indicated:

Goldman-Fristoe -2 Test of Articulation

Phonological Awareness Test

\section{Brain structure}

Documented measurements of the head circumference (occipitofrontal circumference below the 3rd percentile) adjusted for age and gender (during the physical examination at any age including head circumference at birth) and other evidence of functional or structural CNS dysfunction based on a neurologic examination or findings on imaging techniques (computed tomography scan, magnetic resonance imaging, electroencephalogram). Neurologic problems may include seizures not due to a postnatal insult or other signs such as impaired motor skills, neurosensory hearing loss, memory loss or poor eye-hand coordination.

\section{Cognition}

Tests of intellectual functioning include:

Wechsler Intelligence Scale for Children-III (WISC-IV not yet tested for usefulness with the FASD population)

Stanford-Binet- Fourth Edition (SB5 not yet tested for usefulness with the FASD population)

Wechsler Preschool and Primary Scale of Intelligence-III

Differential Ability Scales

Bayley Scales of Infant Development

\section{Communication}

Test batteries of language functioning usually combine both receptive and expressive language functions, as well as single-word and complex functions (sentences and paragraphs). Elicited versus recognition ability (multiple-choice) should be distinguished.

Peabody Picture Vocabulary Test-III

Expressive Vocabulary Test

Preschool Language Scale (3 or 4)

Reynell Developmental Language Scales

Test of the Auditory Comprehension of Language-3

Token Test

Listening Test

Test of Word Knowledge

Clinical Evaluation of Language Fundamentals (Preschool, CELF-3, CELF-4)

These measures are complemented by a language sample analysis that includes: length of utterance, use of complex sentences and word retrieval.

Social Language Observations

Narrative skill (PLS-E story retell); Renfrew Bus Story, Frog Where are You

(Note: Language pragmatics are considered in the domain of social/adaptive skills.) 


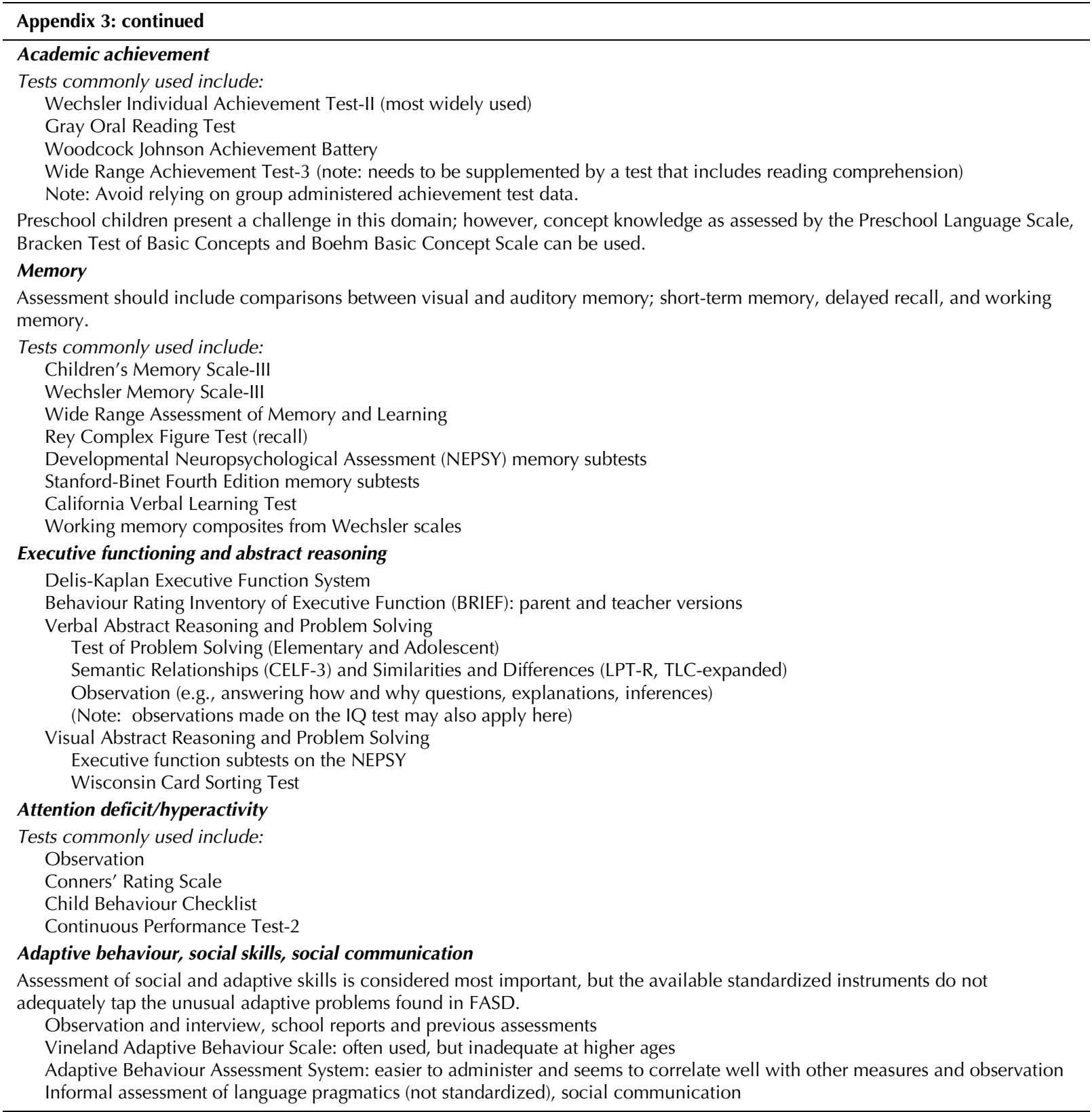

